\title{
A stereotaxic atlas and implantation technique for nuclei of the diencephalon of Atlantic salmon (Salmo salar) parr
}

\author{
RE Peter $1^{*}$, LW Crim 2 , R Billard 3 \\ 1 University of Alberta, Department of Zoology, Edmonton, Alta T6G 2E9; \\ 2 Memorial University of Newfoundland, Marine Sciences Research Laboratory, \\ St John's, Nfid A1C 5S7, Canada; \\ 3 Museum National d'Histoire Naturelle, Laboratoire d'Ichtyologie Générale et Appliquée, \\ 43, rue Cuvier, 75231 Paris Cedex 05, France
}

(Received 16 April 1990; accepted 22 January 1991)

\begin{abstract}
Summary - A stereotaxic apparatus and technique for its inplantation in diencephalic nuclei of Atlantic salmon parr of 20 to $30 \mathrm{~g}$ body weight is described. An atlas of nuclei in the diencephalon is also presented.
\end{abstract}

diencephalic nuclei / stereotaxic apparatus / Salmo

Résumé - Atlas stéréotaxique et techniques d'implantation dans le diencéphale de saumon atlantlque. Un appareil stéréotaxique et les techniques d'implantation dans les noyaux diencéphaliques de saumon atlantique (Salmo salar) parr de 20 a $30 \mathrm{~g}$ sont décrits. Un attas des noyaux dans le diencéphale est aussi présenté.

noyaux de diencéphale / stérétaxie / Salmonidés

\section{INTRODUCTION}

A stereotaxic atlas and technique for diencephalic nuclei is available for a limited number of teleost species, including goldfish, Carassius auratus (Peter and Gill, 1975), killifish, Fundulus heteroclitus (Peter et al, 1975), and rainbow trout, Oncorhynchus mykiss (= Salmo gairdneri) (Billard and Peter, 1982). In the stereotaxic techniques used for goldfish and killifish, the anterior mid margin of the posterior commissure (PC) is used as the zero point, and coordinates are based on measurements from the zero point and brain surfaces. In the technique used for rainbow trout, the zero point is based on skull coordinates and position of the fish in the head holder. When using PC as the zero point, the skull has to be widely opened and the brain exposed. This is relatively easy for fish of a small size. However, this approach may damage the brain and the accessory structures such as the pineal, saccus dorsalis and choroid membrane; the advantage is the generally high precision of sterotaxic placement. Using

- Correspondence and reprints 
external coordinates trauma is minimized; however, the placement is generally less precise and fish of a limited size range from a standardized strain reared under homogeneous conditions are required.

In the present work, an atlas of diencephalic nuclei and a stereotaxic technique, using the PC as zero point, is described for Atlantic salmon (Salmo salar) parr ranging from 20 to $30 \mathrm{~g}$ in body weight.

\section{MATERIALS, METHODS AND RESULTS}

\section{The stereotaxic apparatus}

The apparatus is similar to that used for killifish (Peter et al, 1975). A 3-point system of attachment of the head is used, with a bar against the upper roof of the mouth, and a V-shaped bar on the upper rim of each bony orbital. The dimensions and distances of the orbital bars to the mouth bar, and the base plate, upon which the belly of the fish rests, are shown in figure 1. A micromanipulator for holding an electrode, or tubing for implant or infusion is attached to the base plate.

\section{The fish and surgical procedures}

Wild male and female Atlantic salmon parr, 2 or 3 years of age, were netted in June 1976 and July 1983 from Fitzgerald, near Placentia Bay, Newfoundland, Canada. Males had reached the age of onset of precocious sexual development (gonadosomatic index : $3-4 \%$ ) and females were still sexually immature.

The surgical procedure used for the Atlantic salmon parr was derived from that described for goldfish (Peter and Gill, 1975) and killifish (Peter et al, 1975). Brief- ly, fish were anesthetized in phenoxy ethanol $(0.5 \mathrm{ml} / \mathrm{l})$ and wrapped in a damp tissue paper. Using a circular saw blade, a 3 sided flap was cut in the frontal bone; the most anterior cut was aligned with the posterior margin of the iris of the eyes and the second cut, parallel to the first, was made about $4 \mathrm{~mm}$ further posterior. If this second cut is made more posterior than indicated, damage to the optic tectum is likely occur.

Table I. Nomenclature and list of abbreviations.

AC, anterior commissure
AP, area pretectalis
CM, corpus mamillare
MT, midbrain tegmentum
NAPV, nucleus anteriosis periventricularis
NAT, nucleus anterior tuberis
NDL, nucleus dorsolateralis thalami
NDLI, nucleus diffusus lobi inferioris
NDM, nucleus dorsomedialis thalami
NDTL, nucleus diffusus tori lateralis
NE, nucleus entopeduncularis
NG, nucleus glomerulosus
NH, nucleus habenularis
NLT, nucleus lateralis tuberis
NP, nucleus pretectalis
NPA, nucleus preglomerulosus anterior
NPC, nucleus pretectalis centralis
NPGl, nucleus preglomerulosus lateralis
NPGm, nucleus preglomerulosus medialis
NPO, nucleus preopticus
NPP, nucleus preopticus periventricularis
NPPV, nucleus posteriosis periventricularis
NPS, nucleus pretectalis superficialis
NPR, nucleus pretectalis rotundus
NPT, nucleus posterior tuberis
NRL, nucleus recessus lateralis
NRP, nucleus recessus posterioris
NS, nucleus suprachiasmaticus
NSG, nucleus subglomerulosus
NSV, nucleus saccus vasculosus
NVM, nucleus ventromedialis thalami
OC, optic tectum
P, pituitary
PC, posterior commissure
SV, saccus vasculosus
Tel, telencephalon

$A C$, anterior commissure

MT, midbrain tegmentum

NAPV, nucleus anteriosis periventricularis

NAT, nucleus anterior tuberis

NDL, nucleus dorsolateralis thalami

NDLI, nucleus diffusus lobi inferioris

NDM, nucleus dorsomedialis thalam

NDTL, nucleus diffusus tori lateralis

duncularis

$\mathrm{NH}$, nucleus habenularis

NLT, nucleus lateralis tuberis

NP, nucleus pretectalis

NPA, nucleus preglomeru

NPC, nucleus pretectalis centralis

NPGl, nucleus preglomerulosus lateralis

NPGm, nucleus preglomerulosus medialis

NPO, nucleus preopticus

NPPV, nucleus posteriosis periventricularis

NPS, nucleus pretectalis superficialis

NPR, nucleus pretectalis rotundus

NPT, nucleus posterior tuberis

NRL, nucleus recessus lateralis

NRP, nucleus recessus posterioris

NS, nucleus suprachiasmaticus

NSG, nucleus subglomerulosus

NSV, nucleus saccus vasculosus

NVM, nucleus ventromedialis thalami

OC, optic tectum

(t)

$\mathrm{SV}$, saccus vasculosus 
The third cut, parallel to the longitudinal axis of the fish, connects the first two cuts and was made in the frontal bone on the left side, about $2 \mathrm{~mm}$ above the edge of the orbital bones. Using a scalpel blade, the flap was folded to the right side of the fish along the uncut margin of the flap, and the fish was then clamped in the stereotaxic apparatus. While viewing through a dissecting microscope, and by using fine forceps and small twisted paper swabs to blot up fluids, the saccus dorsalis was pushed gently forward or laterally to the left side and the PC exposed. Throughout the operation, which lasted 5-10 min, the fish were kept cool by placing plastic bags with crushed ice around the body; the gills were not perfused with water during the operation.

Following the brain intervention, the top of the cranial cavity was filled with fish physiological saline (Burnstock, 1958). The frontal bone flap was then replaced and held with surgical silk thread looped across the top of the bone flap and stitched under the skin below the orbital bones. The fish were then returned to aerated and cooled water for recovery from the anesthetic. Survival was generally higher than $90 \%$.

\section{Preparation of the atlas}

The atlas was prepared according to the procedures used for goldfish (Peter and Gill, 1975). Briefly, 5 male and 5 female Atlantic salmon parr weighing between 20 to $30 \mathrm{~g}$ were anesthetized and placed in the stereotaxic apparatus and surgery performed as described above. An insect pin was implanted in the floor of the cranium in the cerebellar region using the electrode holder. The whole head was fixed in Bouin's fixative for $4 \mathrm{~d}$. The implanted electrode was used as a guide for the plane of cross-sectioning. All other histological procedures were carried out according to Peter and Gill (1975). A correction for shrinkage of $3 \%$ (Billard and Peter, 1982) was considered when tracing the grid placed on the left hand side of the drawings.

The atlas is shown in plates $1-X X X \mid$. There were no marked differences in the size and shape of the brain between individuals of different sex and size for the body weight range of $20-30 \mathrm{~g}$. The brain that had been serially sectioned the most symmetrically was selected for photography and mapping of diencephalic nuclei. Sections $0.1 \mathrm{~mm}$ apart were photographed and drawn to scale. Each diencephalic nucleus was outlined on the photographs and drawings, and a grid with lines $0.5 \mathrm{~mm}$ apart placed on the left hand side of each drawing. The drawing labelled 0.0 (plate) shows the zero point in cross section (corresponding to the first section through $P C$ ). All atlas drawings anterior or posterior to 0.0 are indicated as + or - , respectively, with the distance given in $\mathrm{mm}$ from 0.0 . The horizontal zero point from the anterior mid margin of PC was projected on all drawings and served as the reference for vertical positioning of an electrode or other apparatus during the stereotaxic procedure. It was preferable to use the anterior mid margin of $P C$ as horizontal zero rather than the dorsal surface of the brain, as in goldfish (Peter and Gill, 1975) or killifish (Peter et al, 1975), because the highest surface was difficult to evaluate and was not stable in some areas (eg the optic tectum may collapse due to fluid loss following puncture).

\section{Use of the atlas}

After exposing the brain and taking note of the zero coordinates of the anterior mid 

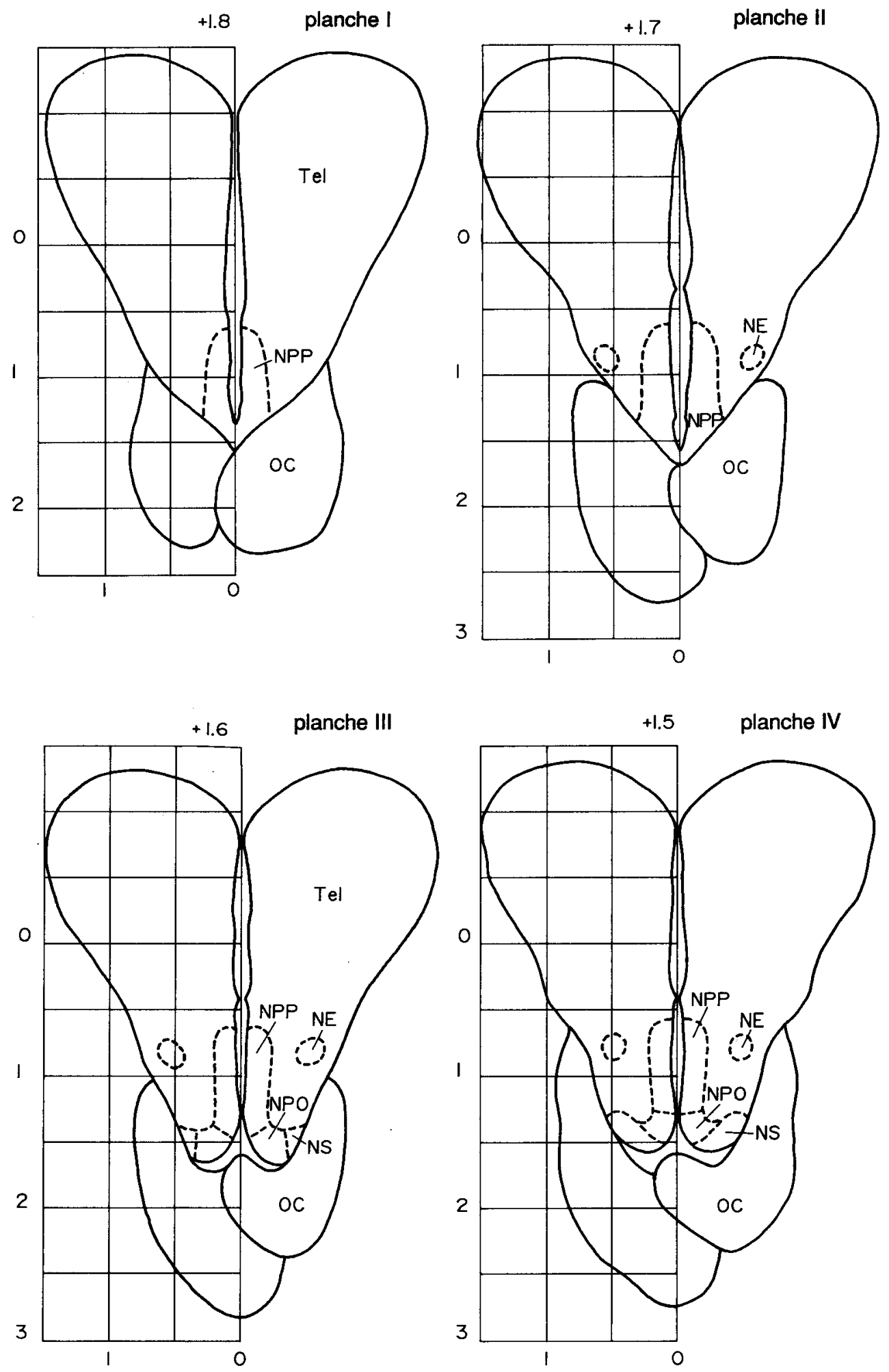
+1.4 planche V
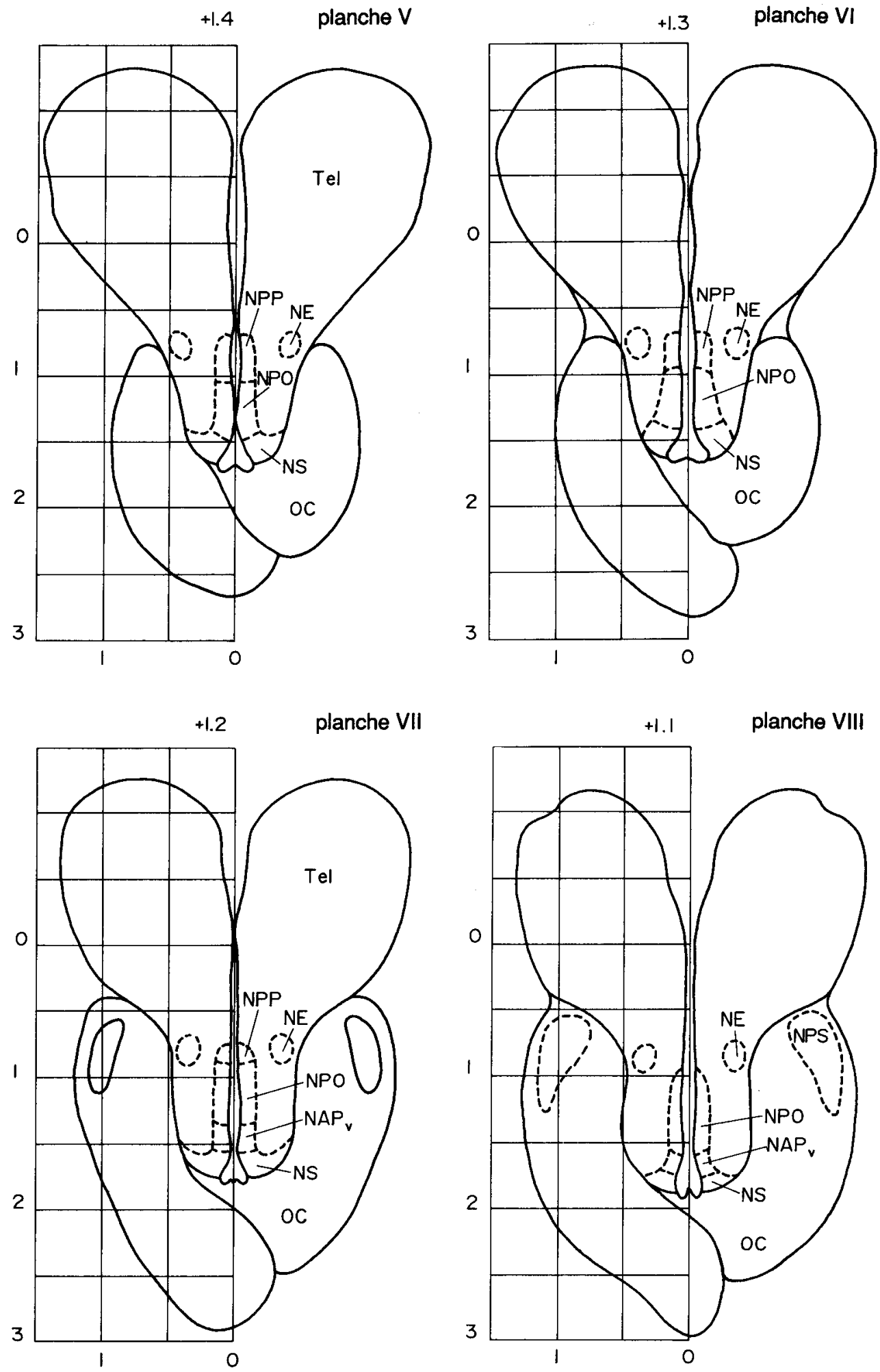


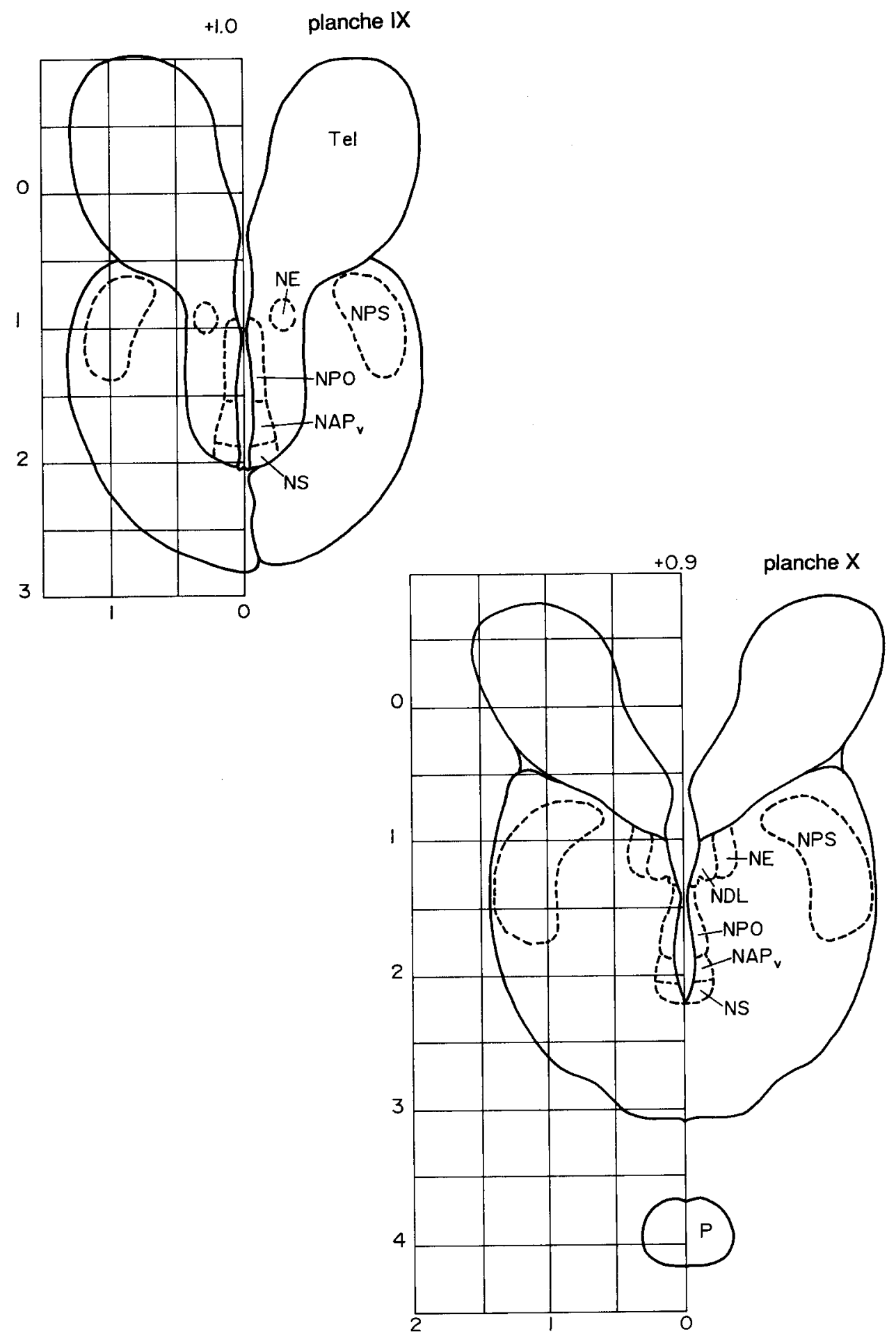




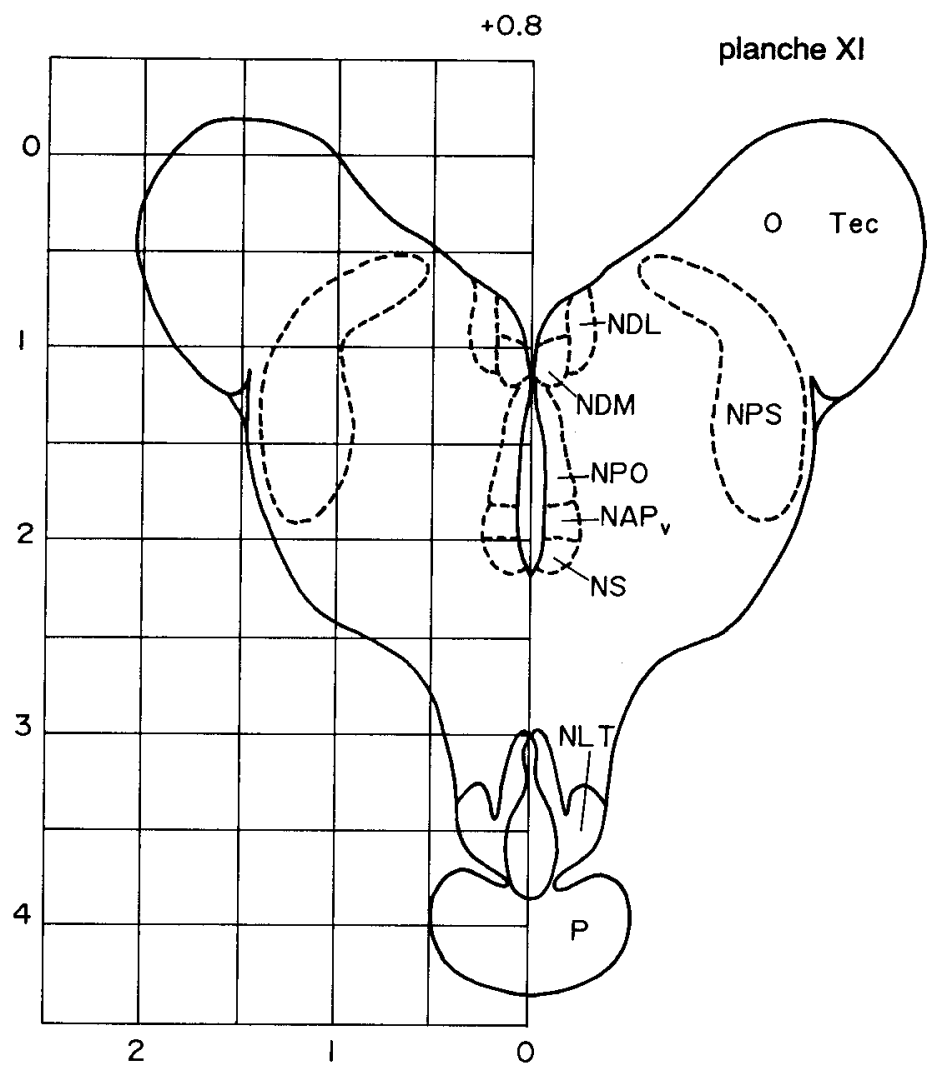

+0.7 planche XII

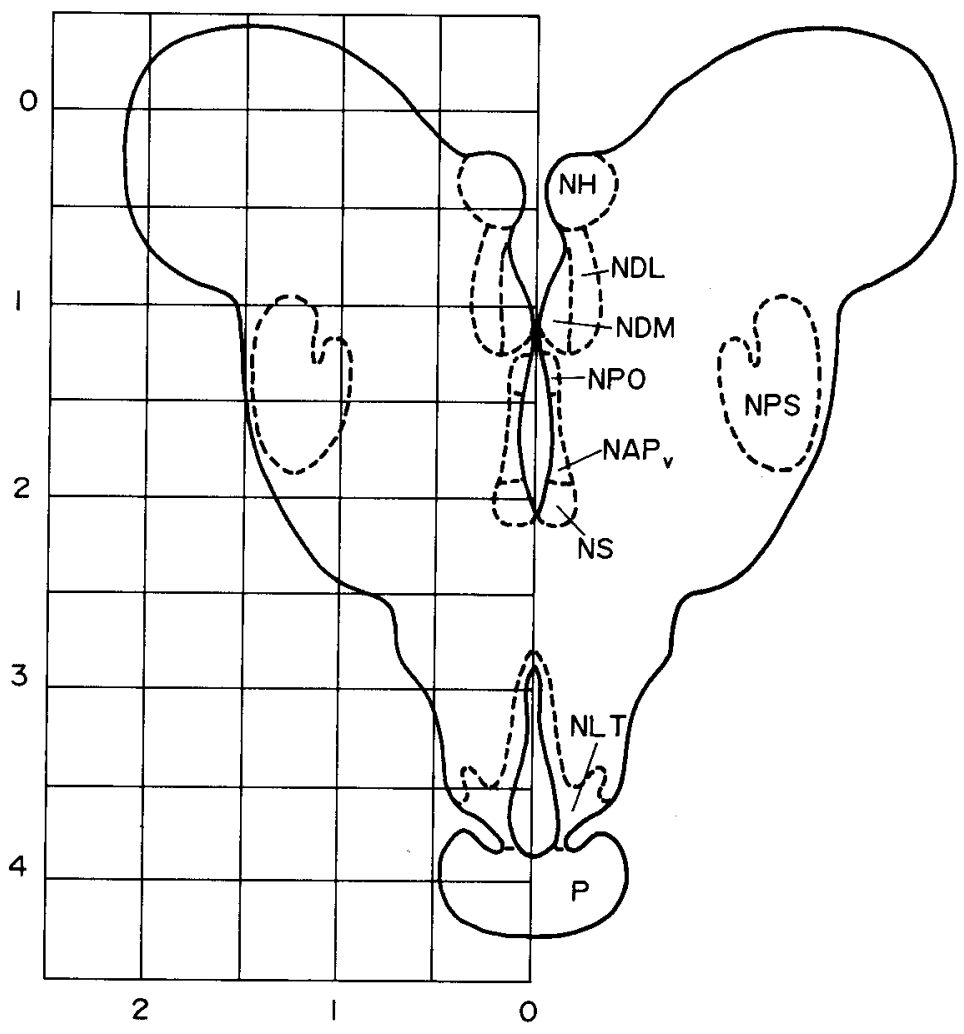



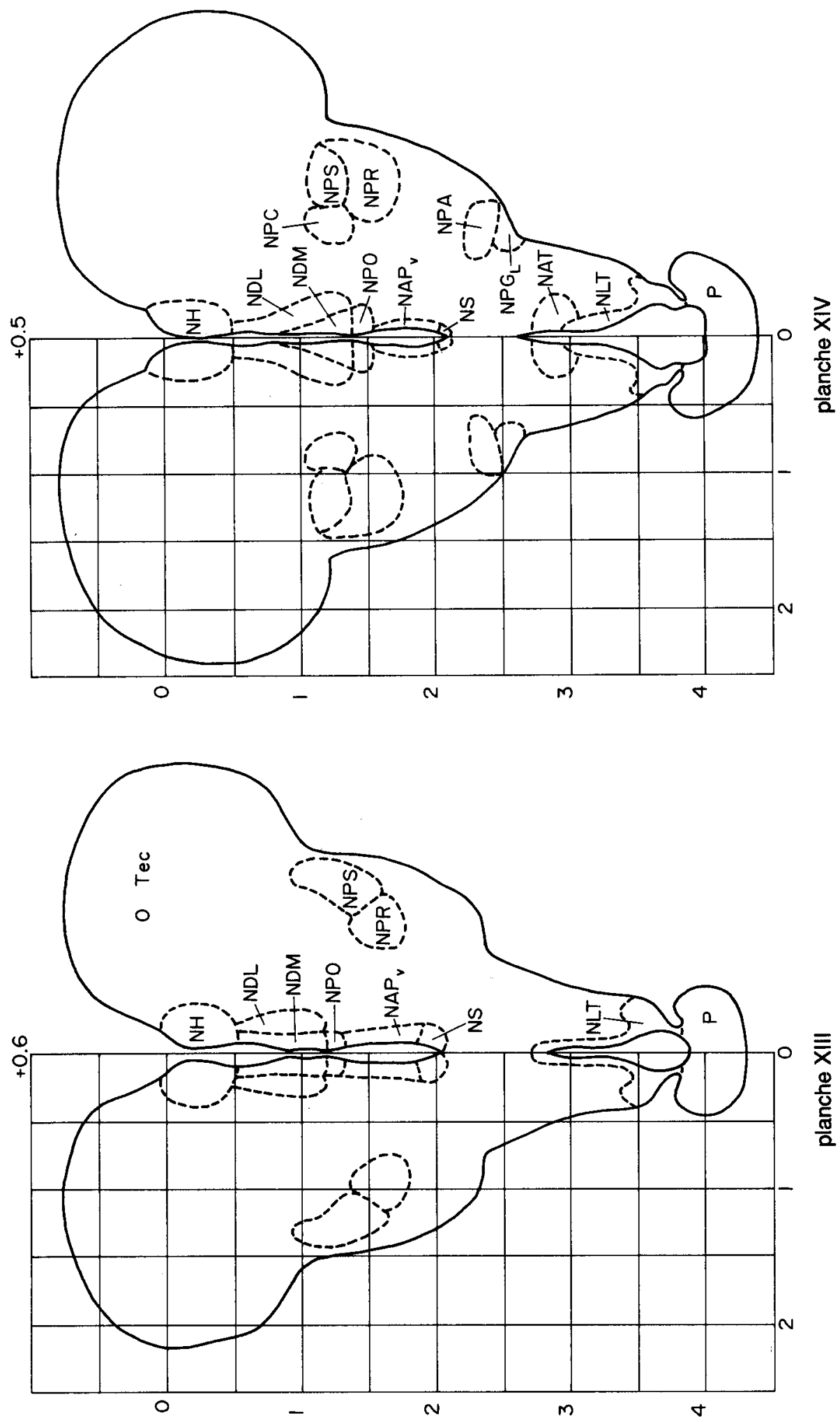

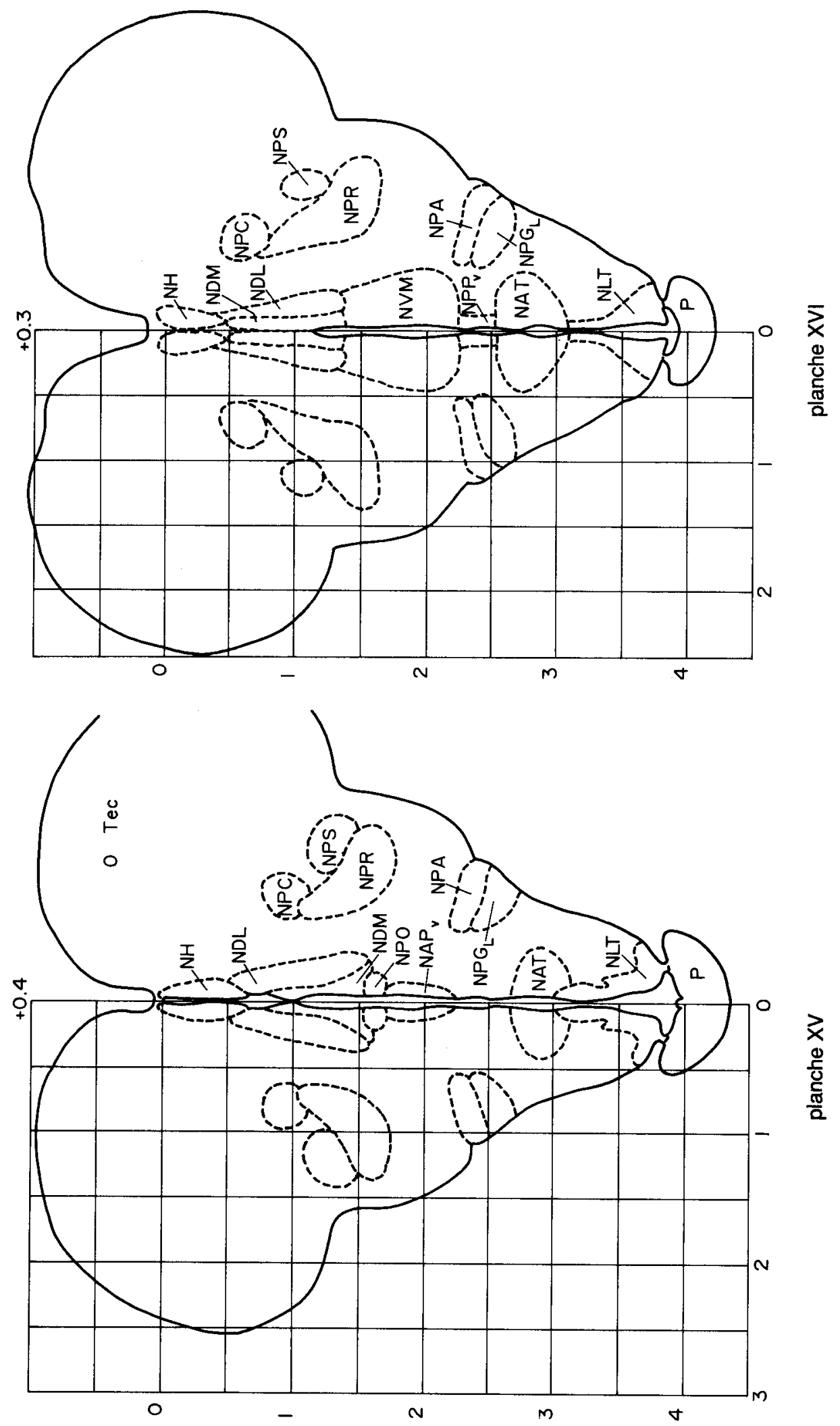

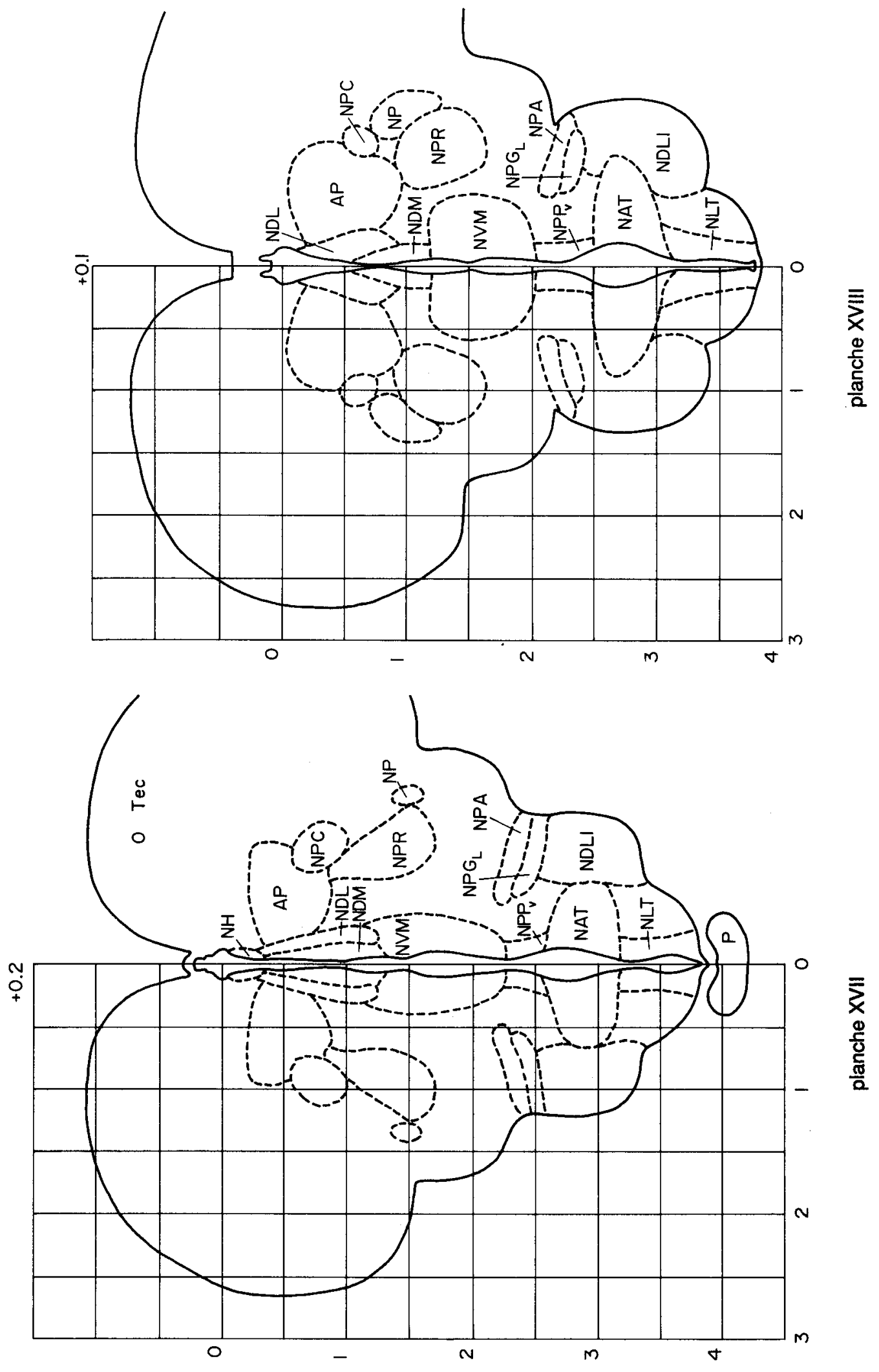

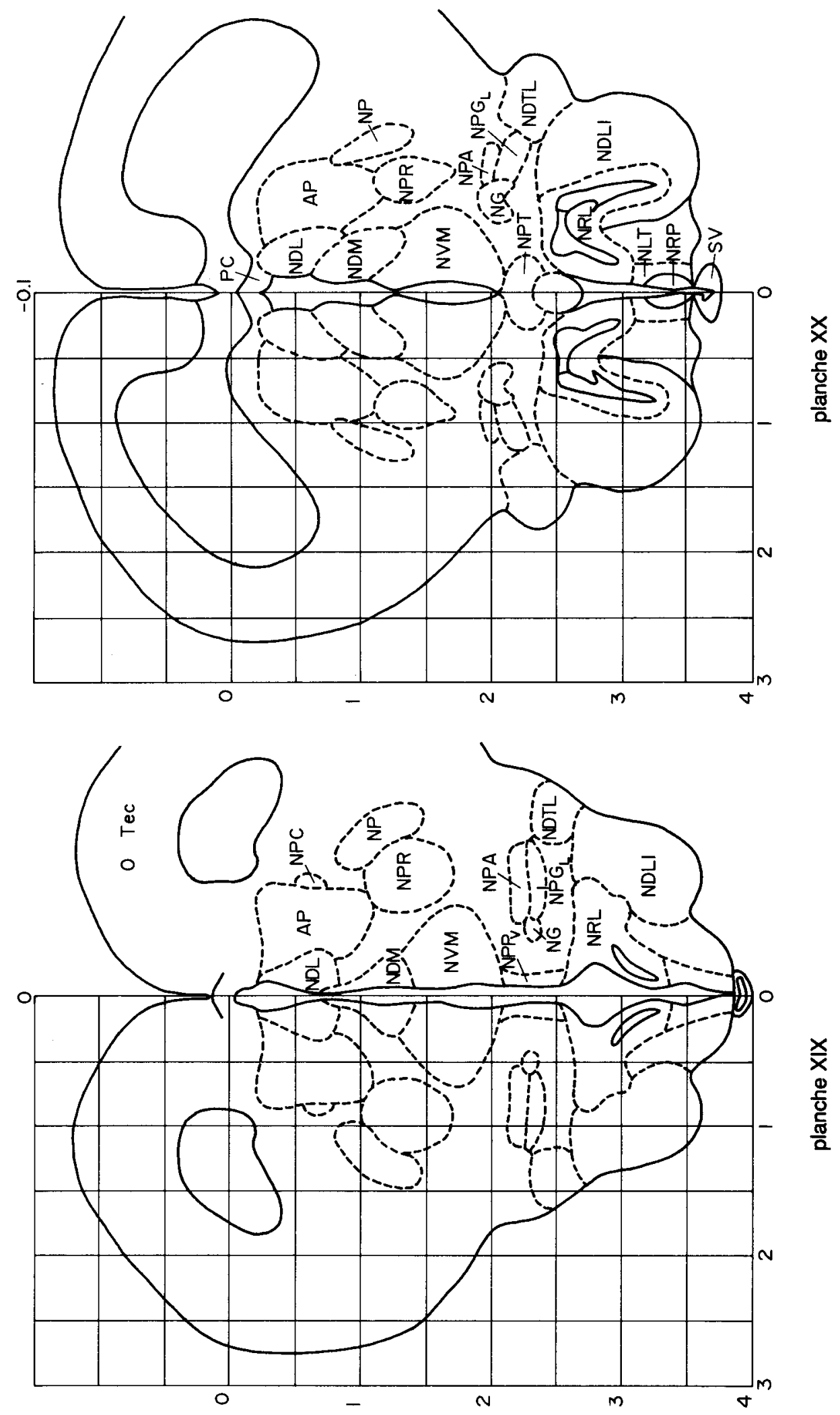

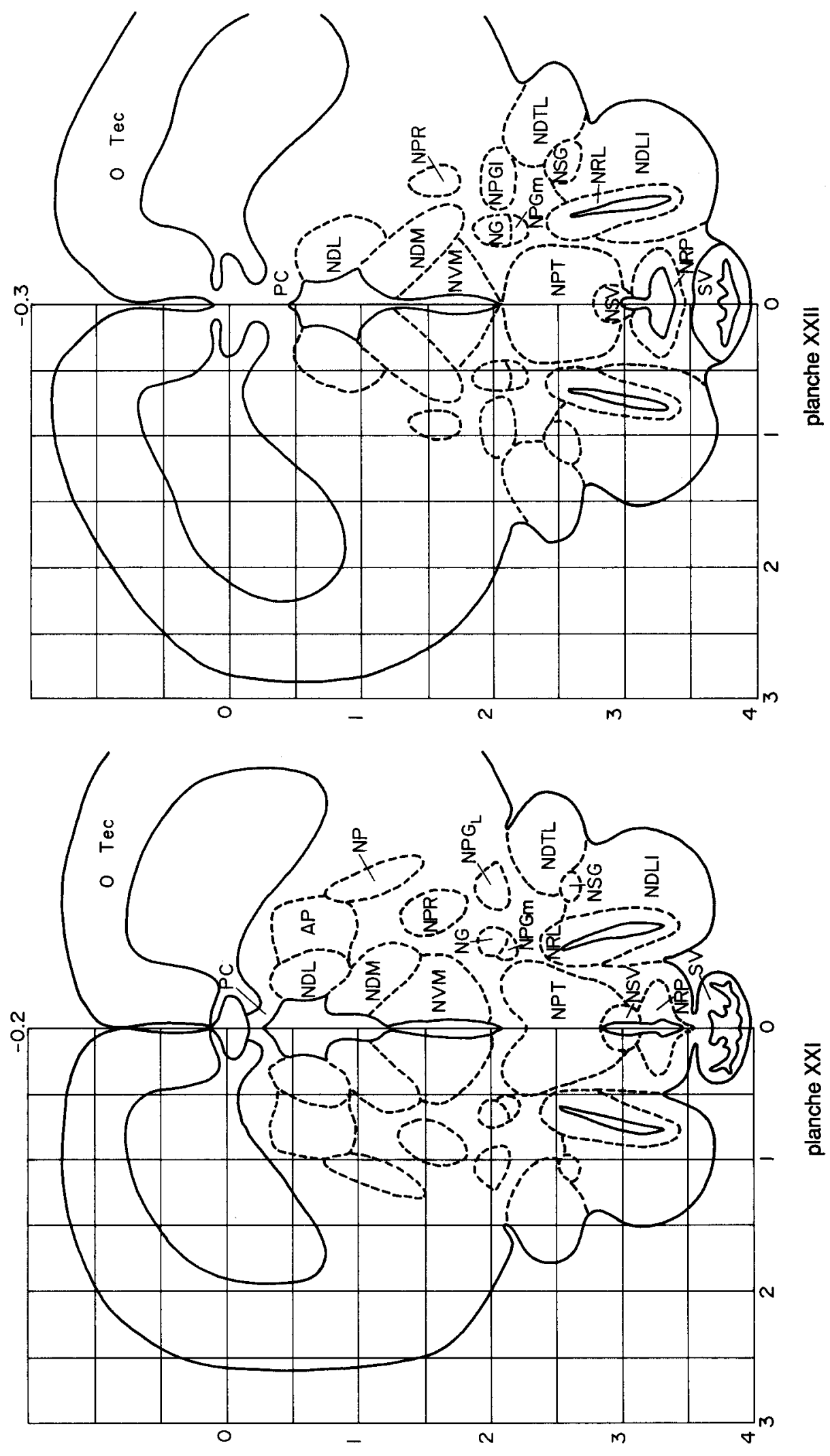

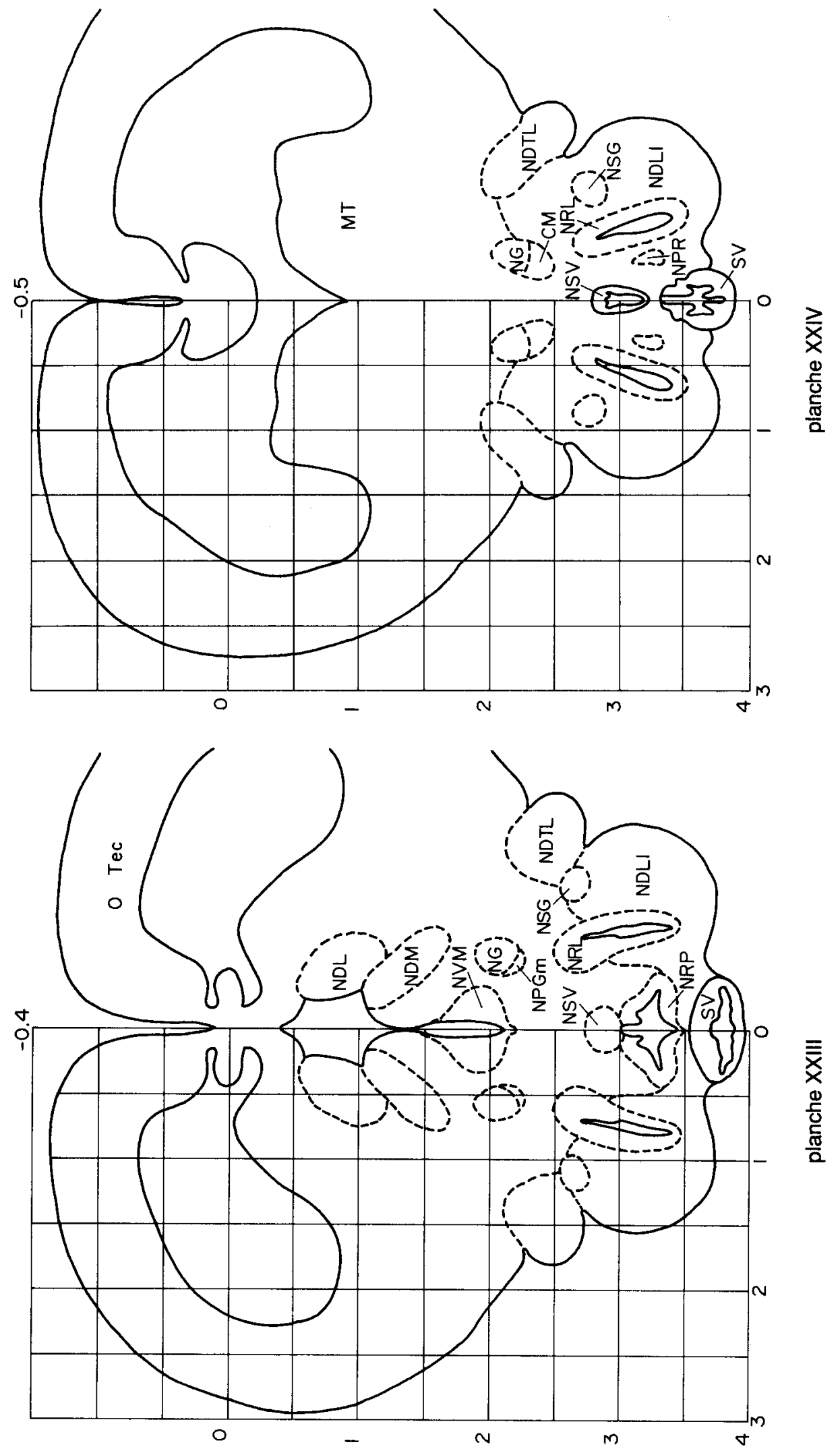

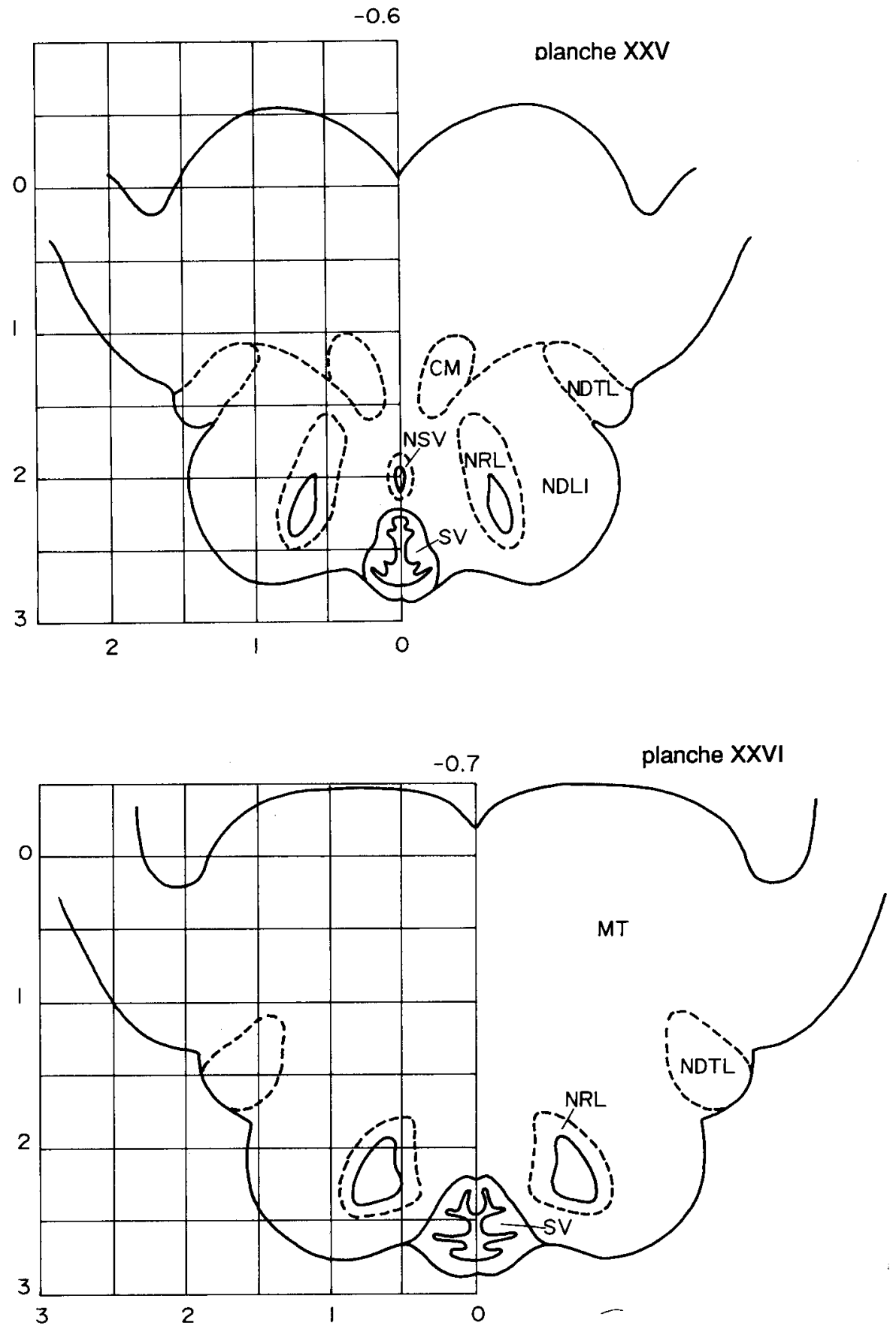

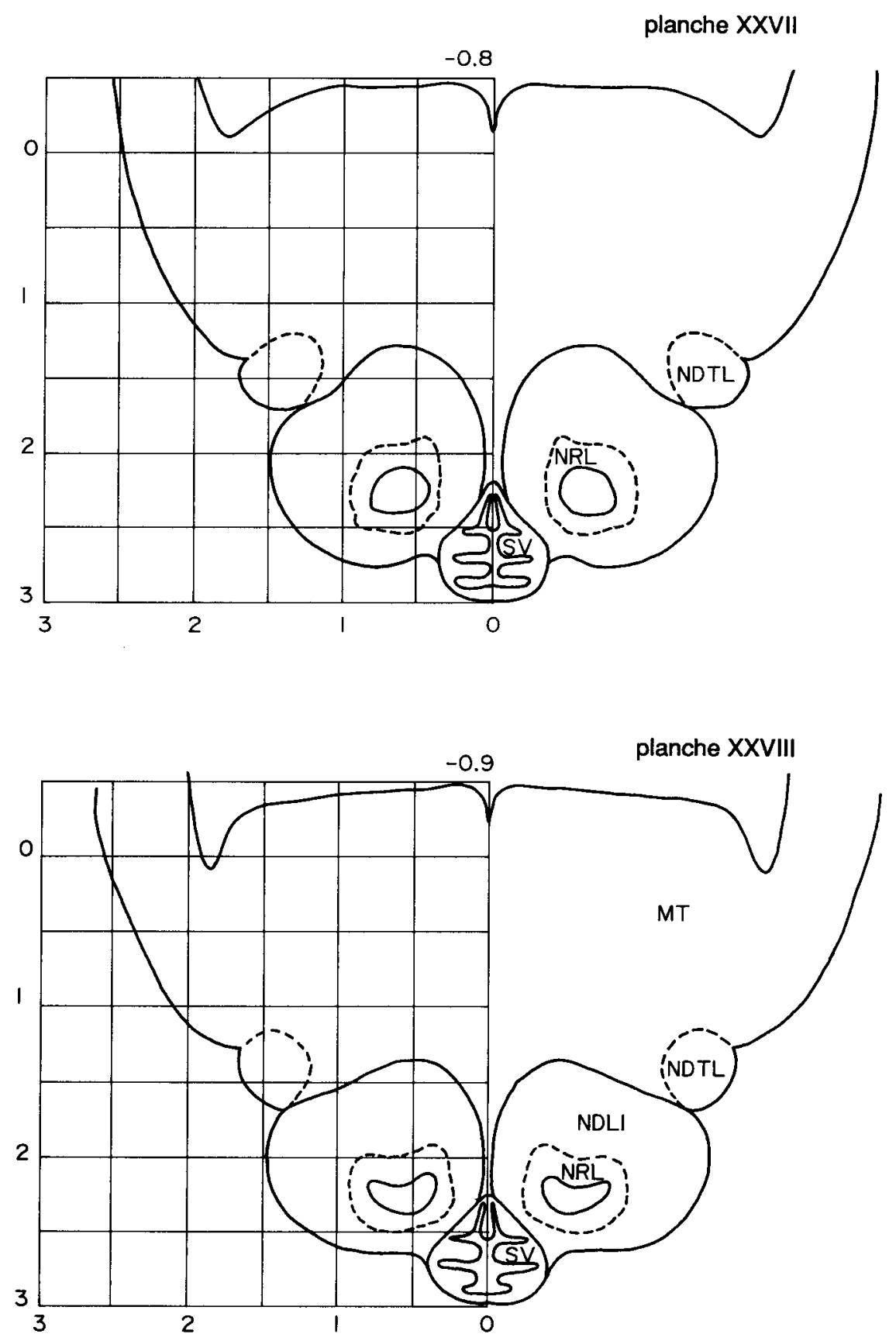

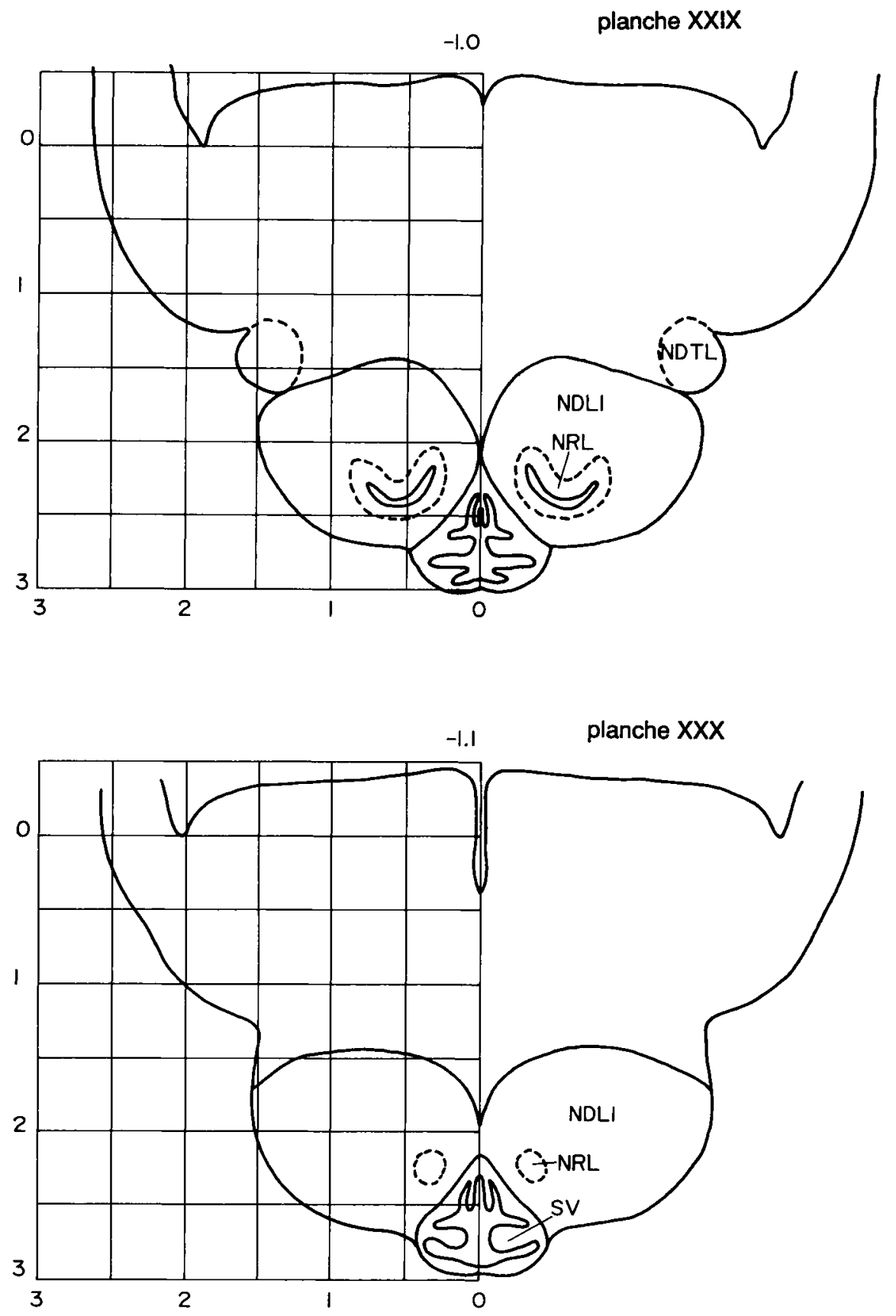
planche $X X X I$

$-1.2$

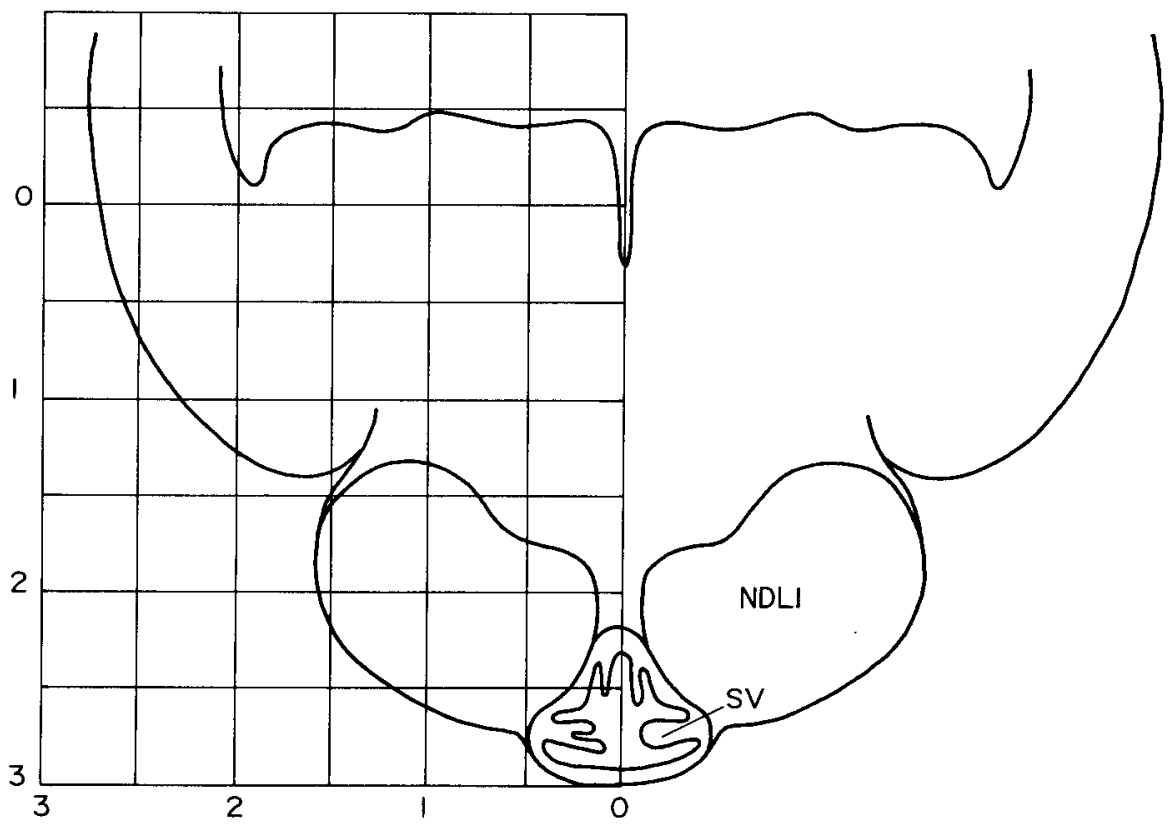

Plates $\vdash \mathbf{X X X I}$. Atlas of the nuclei of the diencephalon of Atlantic salmon parr. The number at the top of each drawing gives the distances in $\mathrm{mm}$ anterior $(+)$ or posterior $(-)$ of the zero point $(0.0)$. The lines of the grid were drawn to scale $0.5 \mathrm{~mm}$ apart. The numbers on the vertical (left) side of each grid give the distances down from the horizontal zero point, as measured at 0.0 at the anterior mid margin of the posterior commissure (PC). The numbers on the bottom side of each grid give the distances from the midline. For key to abbreviations, see table $\mathrm{I}$. 
margin of PC, thereby defining the anterior-posterior and horizontal zeros, the electrode was lifted clear of the brain and moved forward, backward, or laterally, as required for the desired target. The electrode was then returned to the horizontal zero position determined previously, the vertical distance to the target read on the drawing and the electrode moved accordingly. The coordinates for placement and the distances in $\mathrm{mm}$ were expressed as follows: 0.0 , or + or - for distances anterior or posterior, respectively from 0.0 ; midline $(M)$, or distance right $(R)$ and/or left (L) from $M$; depth (D). All values are expressed to the nearest $0.1 \mathrm{~mm}$.

\section{Nomenclature of diencephalic nuclei}

The nomenclature used for the diencephalic nuclei of the Atlantic salmon was the same as that previously used for goldfish (Peter and Gill, 1975), killifish (Peter et al, 1975) and rainbow trout (Billard and Peter, 1982), with some revisions according to Bradford and Northcutt (1983). A suprachiasmatic nucleus was recognized in the goldfish by Bradford and Northcut (1983) on the basis of innervation of the area by fibers from the optic tracts. Consistent with this observation, we have also designated a nucleus suprachiasmaticus, although we have made no attempt to trace optic fibers to this area. Bradford and Northcutt (1983) also renamed most other preoptic nuclei, frequently using size of cell bodies and supposed functional divisions as justification. Such a scheme can be problematic when comparing specimens of different age within a species, or when attempting to develop a nomenclature system that can be applied to several species. Functional subdivisions have already been recognized in the proposed nucleus suprachiasmaticus in addition to the input of op- tic fibers; to illustrate, cell bodies immunoreactive for salmon gonadotropin-releasing hormone have been localized in this region in goldfish (Kah et al, 1986) and rainbow trout (Schafer et al, 1989), and a dopaminergic group of cell bodies has also been reported in this area in goldfish (Kah et al, 1984). Given that there is a continuum of periventricular cell bodies in the preoptic region, and that multiple functional zones will likely be identified, we prefered to maintain the relatively simple nomenclature for preoptic nuclei originally described for goldfish (Peter and Gill, 1975), killifish (Peter et al, 1975) and rainbow trout (Billard and Peter, 1982).

Bradford and Northcutt (1983) recommended renaming large portions of the nucleus lateralis tuberis. We have not followed their proposed scheme, because the terminology of nucleus lateralis tuberis is very widely recognized. Also, a number of functional zones have already been defined for the nucleus lateralis tuberis, some of which overlap (Peter and Fryer, 1983), and it is not clear how any nomenclature scheme can recognize these subdivisions.

In accordance with the recommendations of Bradford and Northcutt (1983), nuclei identified in goldfish (Peter and Gill, 1975), killifish (Peter et al, 1975) and rainbow trout (Billard and Peter, 1982), have been renamed as follows: nucleus anterioris hypothalami to nucleus preglomerulosus anterior, nucleus preglomerulosus pars lateralis to nucleus preglomerulosus lateralis, nucleus preglomerulosus pars medialis to nucleus preglomerulosus medialis, nucleus pregomerulosus pars medialis commissuralis to nucleus preglomerulosus commissuralis, nucleus cerebellosus hypothalami to nucleus subglomerulosus, nucleus rotundus to nucleus pretectalis rotundus, nucleus corticalis to nucleus pretectalis centralis, and nucleus lateralis geniculatus to nucleus pretectalis superticialis. Renaming 
of some other nuclei was also suggested by Bradford and Northcutt (1983) for a variety of reasons; however, we do not agree with these suggestions for reasons similar to those indicated above for preoptic and ventral hypothalamic nuclei.

\section{DISCUSSION}

The stereotaxic atlas and technique described here for Atlantic salmon parr has been used for placement of cocoa butter pellets containing sex steroids in the preoptic region and hypothalamus (Crim and Peter, 1978), and electrodes for lesioning of the diencephalon (Dodd et al, 1978; Crim et al, unpublished results). The average success for placements in this work was $80 \%$, which is similar to the success of placements in the diencephalon of goldfish (Peter and Gill, 1975) and killifish (Peter et al, 1975). Although the size range of Atlantic salmon parr indicated for the sterotaxic technique was $20-30 \mathrm{~g}$, we have applied the technique to parr ranging from $10-40 \mathrm{~g}$ with an overall success rate of about $60 \%$. We hope that this stereotaxic atlas and technique will help to stimulate further research on this species.

\section{ACKNOWLEDGMENTS}

This work was supported by a Visiting Professorship to REP from the Museum d'Histoire $\mathrm{Na}$ turelle, and NSERC Canada grants to REP and LWC.

\section{REFERENCES}

Billard R, Peter RE (1982) A stereotaxic atlas and technique for nuclei of the dlencephalon of the rainbow trout (Salmo gardneri). Reprod Nutr Dov 22, 1-27

Bradford MR Jr, Northcutt RG (1983) Organization of the diencephaton and pretectum of the ray-finned fishes. In: Fish Neurobiology. Vol 2 (Northcutt RG, Davis RE, eds) University of Michigan Press, Ann Arbor, Michigan, 117163

Burnstock G (1958) Saline for freshwater fish. J Physiol (Lond) 141, 35-45

Crim LW, Peter RE (1978) The influence of testosterone implantation in the brain and pituitary on pituitary gonadotropin levels in Atlantic salmon parr. Ann Anim Biochim Biophys 18, 689-694

Dodd JM, Stuart-Kregor PAC, Sumpter JP, Crim LW, Peter RE (1978) Premature sexual maturation in the Atlantic salmon (Salmo salar L). In: Comparative Endocrinology (Gaillard PJ, Boer HH, eds) Elsevier/North Holland Press, Amsterdam, 101-104

Kah O, Breton B, Dulka JG, Nunez-Rodriguez J, Peter RE, Rivier JJ, Vale WW (1986) A reinvestigation of the $\mathrm{GnRH}$ (gonadotropinreleasing hormone) systems in the goldfish brain using antibodies to salmon GnRH. Cell Tissue Res 244, 327-337

Kah O, Chambolle P, Thibault J, Geffard M (1984) Existence of dopaminergic neurons in the preoptic region of the goldfish. Neurosci Lett 48, 293-298

Peter RE, Fryer JN (1983) Endocrine functions of the hypothalamus of actinopterygians. In: Fish Neurobiology Vol 2, (Davis RE, Northcutt RG, eds) University of Michigan Press, Ann Arbor, Michigan, 165-20

Peter RE, Gill VE (1975) A sterotaxic atlas and technique for forebrain nucleic of the goldfish, Carassius auratus. J Comp Neurol 159, 69-102

Peter RE, Macey MJ, Gill VE (1975) A stereotaxic atlas and technique for forebrain nuclei of the killifish. Fundulus heteroclitus. J Comp Neurol 159, 103-128

Schafer H, Schulz R, Blum V (1989) Immunoreactivity of gonadotropin-releasing hormone and gonadotropic hormone in the brain and pituitary of the rainbow trout, Salmo gairdneri. Cell Tissue Res 257, 227-235 